\title{
The Role of Parents in the Use of Media for Early Childhood in Suburban Jakarta
}

\author{
B. Guntarto ${ }^{a}$, Nurina Sevrina ${ }^{b}$ \\ ${ }^{a}$ Lecturer at Universitas Multimedia Nusantara (UMN) Serpong, Tangerang, West Java, Indonesia \\ ${ }^{\mathrm{b}}$ Researcher at Yayasan Pengembangan Media Anak (YPMA), Jakarta, Indonesia \\ e-mail: bobi.guntarto@umn.ac.id
}

\begin{abstract}
The presence of digital media in many children's lives in Indonesia, besides conventional media such as $\mathrm{TV}$, has boomed. Thus, things are changed gradually without being noticed by the parents, starting from the activities that children do during leisure time, children's play, their communication pattern, even their daily life which leading to addiction to digital media. Are parents aware of the change and can they control their children's digital media consumption? How parents understand and address this phenomenon? What actions do parents take to reduce the negative effects and increase the potential of digital media for children `s education and development? This qualitative research involves seventeen middle-class families who have children aged 3-6 years old, living in the capital city Jakarta and suburban cities, Bekasi and Tangerang. The aim of the study is to explore the practice of parental mediation on the activities of their children using media. It discusses the findings from the field research, which grounded on Parental Mediation Theory as well as various media implications in early childhood. The field research finds that most parents are aware of the significance of parental mediation on their children's media consumption, yet, without a consistency and a thorough understanding of the interaction between children and the media. The findings also proposes that it is crucial for parents to have an adequate understanding of how the media works, its effects on children, and alternative activities for children, in order to improve the quality of their parental mediation.
\end{abstract}

Keywords: media and early childhood; parental mediation theory; children media use

\section{INTRODUCTION}

It is not surprising anymore that media has become a part of young children's growth and lives in this digital era. Owning different types of media such as television, computer, the internet, and smartphones is common among families in the modern household. In Indonesia, the integration of internet has reached more than half of the country's population (Kehidupan semakin lekat, 2018). Moreover, preschool-aged children in Indonesia are exposed to the digital media (Yayasan Pengembangan Media Anak [YPMA], 2016).

Thus, in order to build a positive digital environment for children, it is crucial for parents to be involved in their children's media consumption. Scholars have concluded that parents serve a significant role in influencing their children's thoughts on media. Austin (1993) asserts that family communication in which parents discuss the content of media, influence the children's interpretations of television. Discussing television content with the children also helps children in perceiving the real world (Austin, Roberts, \& Nass, 1990). In addition family communication, parents' role in restricting television viewing on their children affects the children's perception of potentially negative effects of television (An \& Lee, 2009) as well as diminishing their proneness to those effects (Nathanson, 1999).

This research aims to further explore the role of parents in their children's media consumption, especially for children in their preschool and kindergarten age. Young children are a crucial topic 
of discussion because early childhood is a crucial stage of development. Potter (2012) argues that in studies of media, children are a unique age group because of their age and life experience. Children at preschool age are on a cognitive development stage where they are self-centered and begin to understand symbolic functions for representation and to learn languages but not capable yet to do reversible operations (Piaget, 1964; Piaget in Fischer, 1980). Therefore, children inevitably learn through the media content besides their parents and schools (Giroux \& Pollock, 2010). Similarly, Steyer (2002) also suggests that television has become "the other parent" for children (p. 7).

Children's media consumption is an important topic to explore further because media has been changing children's behavior and attitude gradually. Digital media has influenced children's play significantly (Rogulj, 2014). Many children prefer digital games to other toys because digital media provide children with more opportunities for social interaction (Lego Learning Institute, 2003). Lego Learning Institute's report in 2003 finds that digital media allows children to interact with more friends without being present physically in a certain place. Similarly, the internet seems to cause changes on cognitive development on the areas such as responding to and taking in social cues or choosing what to pay attention and what to ignore (The United Nations Children's Fund [UNICEF], 2017).

Therefore, children's lives and development are strongly influenced by media. Digital games have a positive impact on children's ability in acquiring foreign language (Aghlara \& Tamjid, 2011). Furthermore, with the easy access to digital media at home and at school, children aged three to four years old are able to create short animated films using editing software (Marsh, 2006). Watching television and playing games increase the children's literacy skills, i.e. reading and writing, beyond what they have learned at school (Vasquez, 2005). However, digital media also give some negative impacts. Children and teenagers experience bullying, sexting, online harassment, and are exposed to pornography content mainly from social media (O'Keeffee \& Carlke-Pearson, 2011). Moreover, addiction to digital or video games may influence children's behavior. According to Scutti (2018), World Health Organization (WHO) categorizes gaming disorder on their International Classification of Diseases (ICD) as a pattern of digital or video gaming behavior. This disorder is characterized by the user's weakened control over gaming, priority to gaming over other daily activities, and continuation of gaming even after the occurrence of negative consequences (WHO, n.d.).

Despite the negative effects that media have on children, there are a number of challenges for parents' involvement regarding the issue. Vittrup (in Vittrup, Snider, Rose, \& Rippy, 2014) asserts that parental concerns and awareness of children's media consumption have yet to be increased. Besides, parents' perception of media that their children consume also influences their mediation; the more positive their perception on a medium, the more often they co-view media in forms of TV and films with their children aged 2-5 years old (Sandstig, 2013). Many parents find it difficult in seeking to balance the educational and social advantages of media use and the drawbacks of media content on their children's safety, behavior, and attitude (Livingstone \& Helsper, 2008).

Similarly in Indonesia, regardless of the parents' academic background or economic status, mediating their children on media use is a challenge as well. According to Luthfia (2018), most parents with higher degree education and are from middle to high economy class may have the knowledge on how to guide their children on consuming media but they hardly find the time to spend with their children for that purpose. On the other hand, middle-class parents may have more time to be spent with their children daily; unfortunately, they have less knowledge on applying an effective mediation on their children's media usage (Luthfia, 2018).

Furthermore, exploring parental mediation in Indonesia is an important area of inquiry. To date, the study of parental mediation at private or home domain tends to focus the Western and developed countries (e.g. Desmond et al., 1985, Livingstone \& Helsper, 2008; Nathanson, 1999; Sandstig, 2013; Valkenburg, Kremar, Peeters, \& Marseille, 1999). Thus, this project contributes to the study of parental mediation at home or private domain in the Eastern and developing countries.

There are several questions that drive this research: Are Indonesian parents aware of the changes in their children because of media consumption? Can they control or regulate their children's digital media use? How they understand and address this phenomenon? What actions do parents take to minimize the drawbacks and maximize the advantages of digital media for their children's education and development? This project 
assesses how parents in Indonesia involve or mediate their children's media consumption.

\subsection{Parental Mediation}

There are various roles and strategies that parents take to be involved in children's media consumption, such as, making rules or restrictions, explaining or discussing the content and co-viewing media with the children (e.g. Austin in Livingstone \& Helsper, 2008; Nathanson, 1999; Sandstig, 2013). This "parental management of the relation between children and media" is called "mediation" (Livingstone \& Helsper, 2008, p. 3). While Nathanson (1999) argues that parental mediation includes simple restrictions, parental monitoring, as well as interpretive strategies, another study limits the notion of mediation only when parents process or translate media content meaning and message for their children to understand its intention, omitting the rule-making and co-viewing (Desmond, Singer, Singer, Calam, \& Colimore, 1985). Although it is important to understand that there are different suggestions on to what extent this concept of mediation is, together they establish the meaning of parental involvement or management on their children's media consumption as suggested by Livingstone and Helsper's study in 2008. Therefore, this paper will include various types of parental involvement in the children's media consumption as parental mediation.

The various definition of parental mediation which discussed above could be organized into three broad strategies of parental mediation. According to Nathanson (1999; 2001), parental regulation is divided into three: active, restrictive, and co-viewing mediation. Similarly, Valkenburg et al. (1999) assert that the strategies that parents take in children's television guiding are co-viewing or parental modeling, restrictive mediation or rule-making, and active or instructive mediation.

Combining the theories, Livingstone and Helsper (2008) propose that these strategies can be applied to all media in a more general form. According to their study, there are three types of parental mediation on children's media consumption:

1. Active mediation is associated with the talking about the content of media while the children are engaging with (watching, reading, listening to) a certain medium. The discussion between parents and children may be in both instructional and critical forms. Instructive mediation is another wording for this term (Valkenburg et al., 1999).

2. Restrictive mediation involves establishing rules that limit or restrict the use of the medium, for instance by controlling the time spent, location, or content. Parents are not commenting on the content or the effects of the medium with their children.

3. Co-using means that the parents and their children use media together. In other words, parents and children are sharing in the same experience with the medium but not discussing the content or its effects. The term co-viewing holds a similar meaning for co-using but only referred to when watching television or films (Sandstig, 2013). Hence, these terms will be used interchangeably during discussions that involve viewing television or film.

This study adopts the more general view of parental mediation as described by Livingstone and Helsper's study in 2008. Parental mediation stresses on parent-child interaction in consuming media which includes discussing of media content, making regulations regarding media consumption or access at home, as well as sharing in the experience by using a medium together.

\section{METHOD}

In order to gather qualitative data, in-depth interviews and non-participant observations were employed as the most appropriate strategies. This multi-methods approach results in a "greater validity and reliability than a single methodological approach" (Gill \& Johnson in Dutton, 2003, p. 26). An in-depth interview is selected in order to explore further one's perspectives on a particular idea (Boyce \& Neale, 2006), which is parental mediation. Furthermore, non-participant observation is suitable for this study because it allows the researchers to capture social action and interaction when it happens during a certain time and location (Caldwell \& Atwal, 2005).

The field research explores families whose at least one child is at preschool and/or at kindergarten age. According to YPMA (2016), pre-school and kindergarten groups consist of children aged 0-7. In total, there are 17 families and 17 children aged 3-7 involved in the research. The interviews and observations are located in Jakarta, Tangerang, and Bekasi. The parents were interviewed first, then the 
children were observed. Although the numbers of members in the family, parents' occupations, and children's living environments are different from one family to another, they come from the middle-class background.

The theoretical framework guiding this study is the three dimensions of parental mediation: (a) active mediation, (b) restrictive mediation, and (c) co-using/co-viewing. In order to examine the parental mediation on children's media use, the interview questions were designed based on the core theory: the amount of time their children spend in engaging with a media, the content of media that their children consume, the effects of media consumption on their children, the rules or regulations applied in the family regarding media use, the amount of time that they spend with their children together to co-use a medium, and if the parents discuss the content of media.

The preschool and kindergarten children in the families were observed directly to delve further into their behavior while engaging to a medium, the actual content of media that they watch, as well as their attitude affected by media consumption. Conducting both interview and observation methods allows the researchers to analyze the reality of parental mediation in a household, i.e. if the parental mediation is done effectively and also if the children obey and/or the parents are strict to the rules and regulations of media consumption at home.

\section{RESULTS AND DISCUSSION}

Digital media has become a crucial part of children's lives. Despite studies have proposed that digital media may influence their development (Bittman, Rutherford, Brown, Unsworth, 2011; Buckingham, 2013), parental concerns and awareness regarding children's media exposure has yet to be increased (Center on Media and Human Development School of Communication Northwestern University, 2014; Vittrup in Vittrup et al., 2014). It is crucial for parents and other responsible adults to be aware of the types and impacts of their children's media usage as well as the kinds of engagement that they need for their children in order to establish a safe digital environment for young children. The following paragraphs will discuss the findings of field research conducted by students of Universitas Multimedia Nusantara (located in Serpong, West Java) and Universitas Pancasila (located in South Jakarta) in the topics related to parental mediations and digital media influences on children.

\section{Time and Media Content}

According to the interviews with the parents, the amount of time a child spends to consume a media is six hours a day but it could be less or more depending on the child's behavior and attitude towards media. During weekdays, most children start watching television or playing their smartphones in the afternoon or after school, in the evening, and at night before going to bed for approximately two hours each period. During the weekends, children mainly start to watch television at six in the morning. However, only in a few families children can spend less than six hours (up to four hours a day) in using media. Children in these families tend to play outside of their house or doing other activities such as drawing, solving a puzzle, or playing dolls, instead of using digital media. On the other hand, there is another situation where a child gets addicted to digital media. Consequently, the amount of time spent to use media at home exceeds six hours and mostly until beyond their bedtime (after eight or nine o'clock at night).

There are various kinds of media content that children in Jakarta and suburban areas frequently consume. The children mainly watch children's cartoons on TV or on Youtube, such as Upin Ipin, BoBoiBoy, Adit \& Sapo Jarwo, and Masha and the Bear. Although girls and boys mostly watch similar programs, there are certain shows that only watched by girls, for instance, Barbie, Frozen, Peppa Pig, and My Little Pony. Additionally, live action programs or videos that children often watch are The Avengers and Harry Potter for boys, and GantengGanteng Serigala for girls. While some of these programs are being aired on national television channels, some could only be accessed through cable television. On top of television programs, many children play games on the smartphones, tablets, and gaming devices such as PlayStation or XBOX. Games such as Plant vs. Zombies, Asphalt, and Mobile Legend are mainly interesting for boys because it includes fighting and racing.

\section{Types of Parental Mediation}

According to the results, there are different parental mediations applied in a family. From 17 families, 16 parents state that they control and limit their children's media use, such as TV, smartphones, and the internet. One family implements active 
mediation; the mother does not limit any use of TV and internet for her preschool girl but giving her guidance on what programs are appropriate to watch.

Among 16 parents who conduct restrictive mediation, 7 parents implement co-viewing and 1 mother applies active mediation in combination to restrictive mediation. It leaves 8 families conduct only restrictive mediation to their children at home. The combination mainly occurs when the parents have more time at home, i.e. parents who stay at home, work from home, or work outside of the home but dedicate their free time to their children.

The interview result shows that the types of restriction made by parents are mostly time and content limitation. Rules and regulations regarding time in each family are different. The most frequent rules regarding time are restricting children to access any digital media and to use any devices after a certain hour, for instance, after seven or ten o'clock at night. Limiting the amount of time for using a certain type medium is also common. As an example, a child can only play games on smartphones for thirty minutes a day or watch television only for one to two hours a day. Other parents use digital media as a reward system: if their children have finished doing their homework, they are allowed to use media for a certain amount of time.

Despite the rules, in reality, many children exceed the assigned hours to use digital media at home. This mostly occurs in the families where parents hardly stay at home due to work or if the parents are not strict enough to their own children. The observation results find that a child throws a tantrum and cry if his parent takes his smartphone from him after he has used it for hours; the parent has no choice other than let him use the medium longer to make the child remains calm. Another case is in Bekasi, where the parents are not present at home but instead, the relatives - a grandmother and an aunt - are there to take care of the child. In that family, the parents have established a certain time restriction for the child to follow but they are mostly at work during the days, thus the rules are not working effectively. The extended family members seem to be not as strict as the parents and consequently, the child becomes less obedient to the rules and use media as much as he wants in a day.

On top of restrictions on time, parents conduct media content restrictions. A large number of parents interviewed answered that they only let their children watch cartoon or animations on TV as well as on the internet. Besides animation, some parents only allow their children to watch or consume a medium that has no violence in it. In order to control the child's choice of media content, a mother of a kindergarten boy in Tangerang creates a specific folder on Youtube for her son to watch.

As previously discussed, there are parents who combine restriction mediation with co-using. A stayat-home mother admits that she co-views her children in watching television and films, besides regularly reminding them about the media rules at home. Another mother approaches the mediation a little different: she co-uses the content for twenty minutes while her son is engaged to a medium in an hour. In other words, if in a day her son spends six hours to use the internet, then she co-uses the internet for two hours. Other parents co-use media with their children without a specific amount of time, for instance during meal time or leisure time, where mostly the parents choose what to watch, rather than the child selects it for themselves.

The interview results discover that a number of parents provide children with alternative activities in addition to parental mediation. A few parents who work outside home and cannot control their children's media use during weekdays, they supply their children with toys, such as dolls, LEGO bricks, or clay, and activities, such as drawing and coloring. Some parents also take their children for a recreation, shopping at malls, and travelling out of town on the weekends in order to shift their children's focus to the environment instead of digital media. Parents who provide their children with substitute activities to using digital media explain that they want to prevent their children from getting addicted to using media.

\section{The Effects on Children}

The field observations evidently show that digital media gives impacts on the children's behavior and communication skills. The children participating in the research who spend more time with TV and the internet not only become more addicted to the media but also imitate the character's traits from the shows. While some imitations such as fighting, jumping or running may be considered as aggressive, other impersonations are more supportive for their brain development such as, memorizing, singing, speaking in a different language, or dressing up themselves. Moreover, getting addictive also make them respond slower to 
their parents who call their name, have a problem with two-way communication, or have a speech delay.

In regards to the detrimental effects of media on children, parents alter their mediation. According to the interviews, many parents admit that they change the rules and regulations on their children's media consumption after they figure that the media give negative impacts on their children. The common negative effects identified by parents are children's use of inappropriate words, ignorance of their surroundings, and their physical aggressiveness. In the new-adjusted rules, parents mostly become more strict in restrictions on media content (e.g. if the rules previously allowed the child to watch any kinds of cartoons and play games, in the new rules, parents forbid the child to watch cartoon with violence on it or they will take the media from the child). Another parent in Jakarta informs that they also become more active in informing and discussing that media content is not supposed to be imitated in real life.

However, it is not impossible to minimize the negative impacts of media on children through parental mediation. Children do not get addicted to media live in a family where parents can guide their children's media or can supply their children with alternative activities besides using media. The aforementioned mother who advised her daughter on what to watch on TV, resulting in the child play more with other children and only spend a limited time to use the internet or watch TV. Furthermore, compared to using digital media, children seem to be more interested in replacement activities provided by parents, such as drawing, coloring, playing outside of their house, and going out together for recreation.

In conclusion, there are various kinds of parental mediation conducted in a family. The mostapplied parental mediation is making rules for the children's media consumption. Furthermore, it is common for parents to combine restrictive mediation with other mediation such as co-use and active mediation. The field research shows that to some extent, parental mediation has impacted the children's behavior regarding media consumption as well.

\section{Discussion}

Parents play a crucial role in mediating the impacts of media consumption on children. Parents living in Jakarta and its sub-urban areas have applied three types of parental mediation on their children: restrictive mediation, co-using/co-viewing, and active mediation. The mediation is conducted differently from one family to another. Parental awareness on the children-media relationship and parental capability in controlling their children's media consumption serve a major part in supporting the children to become a wise user of digital media. However, these are the essential points which parents in Jakarta and sub-urban cities required to improve.

This study illustrates that although parents are aware of the significance of parental mediation on their children's media consumption, it is done without a consistency and a thorough understanding of children-media interaction. Parents are conscious of media may give impacts on their children's behavior and lifestyle. Nevertheless, the awareness is limited to how long the children are allowed to engage with a medium and what kind of content it portrays. Thus, parents' main concerns are focused on restricting time consumption and selecting media content for their children. Parents do not address this phenomenon earnestly until they came to a realization that their children are negatively affected by media. Unless they witness a significant change in their children's attitude and behavior, parents would not adjust their mediation or parenting style. This demonstrates that parents in Jakarta and suburban areas lack an understanding of how media works and how it affects children. This inadequate knowledge, unfortunately, creates an inconsistency in their parental mediation.

In order to improve consistency in mediating the impacts of media on their children, it is necessary for parents to be strict with the rules and regulations they create. Parental mediation would not be effective unless parents are discipline and doing it continuously. For instance, restrictions on time must be followed by all family members, including parents themselves and the children. However, in an extended family, the employment of rules and regulations become a challenge because normally, parents are replaced by the relatives to take care of the children during the day. Therefore, it is important for parents to cooperate with the children's guardians living at the house in conducting the rules and regulations on media consumption. The researchers argue that by doing so, parents would be able to employ their 
consistency and seriousness in mediating their children.

To a certain extent, parents in Jakarta and suburban areas can control their children's media consumption. They have established a number of rules and regulations on their children's media consumption. In addition to that, it is common for parents to combine a mediation with another. Mainly, parents integrate restrictive mediation with co-using or co-viewing. However, how this combination influences the children's behavior towards the media is still left unknown.

On the other hand, restrictive mediation appears to be the mediation that manifests a significant impact on children's behavior towards media. Discussing media content with children and informing them about the effects of media consumption help children to decide for themselves when to use media and consequently, they become less addicted to them. This corresponds with Lee and Chae's (2007) study which finds that parental active involvement in children's media use has positive outcomes on children's media activities. However, it is unfortunate that there are only a few parents in Jakarta and sub-urban areas who employ this type of mediation. Therefore, it is necessary for Indonesian parents to start applying active mediation to their children. Without combining active mediation, restrictive and co-use mediation cannot prevent children from getting addictive to digital media. Hence, parents are encouraged to increase their communication with their children, for instance, by asking what kind of shows they watch, what they like about the games they play or explaining why a certain behavior on TV is not appropriate to be imitated. It is necessary for parents to establish an open communication for their children, creating an atmosphere where the children can express their thoughts freely on media content that they consume. Thus, to maximize the advantages of digital media on children's life, conducting active mediation is desired.

Parents who tend to reprimand their children on their media use appear to make the children afraid to be open. If active mediation could be done wisely and continuously by parents, children will understand that there are rules they need to obey in using media, hence, media should be consumed wisely. Moreover, children will be accustomed to using media by following a certain regulations. In the future, they will become a wise digital media consumer.
Regarding this situation, the roles of early childhood education teachers are significant in order to establish and reinforce the rules and regulations in children's media consumption. In the practice, early childhood education teachers could become the initiator of the regulations in media consumption and the parents at home support it. Therefore, it is paramount for parents and early childhood educators to attune their views on children-media interaction and the actions need to be taken to create a positive relationship between children and media.

Even though parents in Jakarta and sub-urban cities can control their children's media use, their actions are left with much rooms of improvement, especially in order to minimize the disadvantages of digital environment for their children. Another vital enhancement that parents are required to do is providing alternative or substitute activities to using digital media for their children. Children whose parents let them do more activities in drawing, coloring, playing outside, or going out together for recreation will inevitably find those activities more interesting than watching TV and they are not addicted to using media. Besides, it supports the children's growth and togetherness with other family members.

Thus, in order to improve the quality of parental mediation, empowering parents regarding children's media consumption is fundamental. The parent empowerment activities could be in a form of seminar, readings on parenting in media consumption, or trainings on literacy media for parents. Additionally, to control the negative impacts of media on children, it is necessary for public domain to be involved as well. In other words, government institutions such as Ministry of Women's Empowerment and Child Protection (KPPPA), Ministry of Education and Culture, and Indonesian Children Protection Commission (KPAI) should collaborate with local and international nongovernmental organizations which have programs on empowering parents.

This study emphasizes on parental mediation challenges in Indonesia and has suggested some solutions to the problems. Further research should include parents from different economic and social background and deeply question parents what drives them doing such mediations, what they understand or not understand about these phenomena. This will enable us to delve more into the challenges of parental mediation in Indonesia. 


\section{CONCLUSION}

Parents in Jakarta and sub-urban cities are aware of media influence on their children and can mediate their children's media consumption. However, the parental mediation is inconsistent and lacking an in-depth understanding or information on the children-media relationship. Thus, it is crucial for parents to improve their mediation by becoming more strict with the rules and regulations they establish at home, starting to communicate or discussing the media content with their children (i.e. conducting active mediation), as well as providing alternative activities for their children to do instead of using digital media. Furthermore, the coordination between parents and early childhood education teachers is no less important for creating an effective parental mediation at home. All in all, this is for the more positive digital environment in Indonesia.

\section{REFERENCES}

[1] Aghlara, L., \& Tamjid, N. H. (2011). The effect of digital games on Iranian children's vocabulary retention in foreign language acquisition. Proceedings of the Social and Behavioral Sciences, 29, 552-560. doi: 10.1016/j.sbspro.2011.11.275

[2] An, S. \& Lee, D. (2009). An integrated model of parental mediation: The effect of family communication on children's perception of television reality and negative viewing effects. Asian Journal of Communication, 20(4), 389403, doi: 10.1080/01292986.2010.496864

[3] Austin, E. W. (1993). Exploring the effects of active parental mediation of television content. Journal of Broadcasting \& Electronic Media, 37(2), 147-158. doi: 10.1080/08838159309364212

[4] Austin, E. W., Roberts, D. F., \& Nass, C. I. (1990). Influences of family communication on children's television-interpretation process. Communication research 17(4), 545-564. doi: 10.1177/009365090017004008

[5] Bittman, M., Rutherford, L., Brown, J., \& Unsworth, L. (2011). Digital natives? New and old media and children's outcomes. Australian Journal of Education, 55(2), 161-175. doi: $10.1177 / 000494411105500206$

[6] Boyce, C., \& Neale, P. (2006). Conducting indepth interviews: A guide for designing and conducting in-depth interviews for evaluation input. Retrieved from http://dmeforpeace.org/sites/default/files/Boyce In\%20Depth\%20Interviews.pdf (accessed 29 July 2018)

[7] Buckingham, D. (2013). Making sense of the 'digital generation': Growing up with digital media. Self \& Society, 40(3), 7-15. doi: 10.1080/03060497.2013.1108427

[8] Caldwell, K., \& Atwal, A. (2005). Nonparticipant observation: Using video tapes to collect data in nursing research. Nurse Research, 13(2), 42-54. doi: 10.7748/nr2005.10.13.2.42.c5967

[9] Center on Media and Human Development School of Communication Northwestern University. (2014). Revised parenting in the age of digital technology: A national Survey. Retrieved from https://cmhd.northwestern.edu/wpcontent/uploads/2015/06/ParentingAgeDigitalT echnology.REVISED.FINAL_.2014.pdf (accessed 1 June 2018)

[10] Desmond, R. J., Singer, J. L., Singer, D. G., Calam, R., \& Colimore, K.' (1985). Family mediation patterns and television viewing: Young children's use and grasp of the medium. Human Communication Research, 11(4), 461480. doi: 10.1111/j.1468-2958.1985.tb00056.x

[11] Dutton, C. (2003). Mentoring: The contextualisation of learning - mentor, protégé and organisational gain in higher education. Education + Training, 45(1), 22-29. doi: $10.1108 / 00400910310459644$

[12] Fischer, K. W. (1980). A theory of cognitive development: The control and construction of hierarchies of skills. Psychological Review, 87(6), 477-531. doi: 10.1037/0033295X.87.6.477

[13] Giroux, H. A., \& Pollock, G. (2010). The mouse that roared: Disney and the end of innocence. Maryland: Rowmand \& Littlefield.

[14] Kehidupan semakin lekat dengan internet [Life has become closer to the internet]. (2018, February 20), Kompas, p. 12.

[15] Lee, S. \& Chae, Y. (2007). Children's internet use in a family context: Influence on family relationships and parental mediation. CyberPsychology \& Behavior, 10(5), 640-644. doi: $10.1089 / \mathrm{cpb} .2007 .9975$

[16] Lego Learning Institute. (2003). The changing face of children's play culture: Children's play, learning and communication in a technology driven world. Retrieved from http://www.carsten-jessen.dk/Play_Culture.pdf (accessed 26 July 2018)

[17] Livingstone, S. \& Helsper, E. (2008). Parental mediation and children's internet use. Journal of Broadcasting \& Electronic Media, 52(4), 581599. doi: $10.1080 / 08838150802437396$

[18] Luthfia, A. (2018). Online opportunity dan reduksi online risk melalui lingkungan sosial remaja [Online opportunity and online risk reduction through social environment of teenagers] (Doctoral dissertation, University of Indonesia, Indonesia).

[19] Marsh, J. (2006). Emergent media literacy: Digital animation in early childhood. Language and Education, 20(6), 493-506. doi: 10.2167/le660.0

[20] Nathanson, A. I. (1999). Identifying and explaining the relationship between parental mediation and children's aggression. 
Communication Research, 26(2), 124-143. doi: $10.1177 / 009365099026002002$

[21] Nathanson, A. I. (2001). Parent and child perspectives on the presence and meaning of parental television mediation. Journal of Broadcasting \& Electronic Media, 45(2), 201220. doi: 10.1207/s15506878jobem4502_1

[22] O’Keeffe, G.S., \& Clarke-Pearson, K. (2011). The impact of social media on children, adolescents, and families. Pediatrics, 127(4), 800-804. doi: 10.1542/peds.2011-0054

[23] Piaget, J. (1964). Part I: Cognitive development in children: Piaget development and learning. Journal of Research in Science Teaching, 2(3), 176-186. doi: $10.1002 /$ tea.3660020306

[24] Potter, W. J. (2012). Media literacy 6th ed. California: Sage.

[25] Rogulj, E. (2014). Influence of the new media on children's play. Croatian Journal of Education, 16(1), 267-277. Retrieved from https://www.semanticscholar.org/paper/Influenc e-of-the-New-Media-on-Children-

$\%$ E2\%80\%99-s-Play-

Rogulj/17b00ee12bf2525618cab883de0a17a263 993976

[26] Sandstig, G. (2013). The influence of parental perceptions of media influences on coviewing/using media and instructive mediation with younger children. Journal of Mass Communication and Journalism, 3(163), 1-5. doi: 10.4172/2165-7912.1000163

[27] Scutti, S. (2018, Juni 18). WHO classifies 'gaming disorder' as mental health condition. CNN. Retrieved from https://edition.cnn.com/2018/06/18/health/video -game-disorder-who/index.html (accessed 16 July 2018)
[28] Steyer, J. P. (2002). The other parents: The inside story of the media's effect on our children. New York: Atria Books.

[29] The United Nations Children's Fund. (2017). The state of the world's children 2017: Children in a digital world. Retrieved from https://www.unicef.org/publications/files/SOW C_2017_ENG_WEB.pdf

[30] Valkenburg, P. M., Kremar, M., Peeters, A. L., \& Marseille, N. M. (1999). Developing a scale to assess three different styles of television mediation: "Instructive mediation." "restrictive mediation," and "social coviewing". Journal of Broadcasting \& Electronic Media, 43(1), 52-66. doi: 10.1080/08838159909364474

[31] Vasquez, V. (2005). Resistance, power-tricky, and colorless energy: What engagement with everyday popular culture texts can teach us about learning, and literacy. In J. Marsh (Ed.), Popular culture, new media and digital literacy in early childhood (pp. 153-165). New York, NY: RoutledgeFalmer.

[32] Vittrup, B., Snider, S., Rose, K. K., \& Rippy, J. (2014). Parental perceptions of the role of media and technology in their young children's lives. Journal of Early Childhood Research, 14(1), 4354. doi: 10.1177/1476718X14523749

[33] World Health Organization. (n.d.). Retrieved from http://www.who.int/features/qa/gamingdisorder/en/ (accessed 16 July 2018)

[34] Yayasan Pengembangan Media Anak [Child's Media Development Foundation]. (2016). Media dalam kehidupan anak [Media in Children's Lives]. Jakarta, Indonesia: Yayasan Pengembangan Media Anak 